\title{
Managing psychogenic pseudosyncope: Facts and experiences
}

\author{
Martijn R. Tannemaat ${ }^{1}$, Roland D. Thijs ${ }^{1,2,3}$, J. Gert van Dijk ${ }^{1}$ \\ ${ }^{1}$ Department of Neurology and Clinical Neurophysiology, \\ Leiden University Medical Centre, Leiden, the Netherlands \\ ${ }^{2}$ SEIN-Stichting Epilepsie Instellingen Nederland, Heemstede, the Netherlands \\ ${ }^{3}$ NIHR University College London Hospitals Biomedical Research Centre, Department of Clinical and \\ Experimental Epilepsy, UCL Institute of Neurology, Queen Square, London, United Kingdom
}

\begin{abstract}
Psychogenic pseudosyncope (PPS) is a common cause of apparent transient loss of consciousness (TLOC) with a dramatic impact on the quality of life. This review aims to give an overview of the definition, incidence, etiology, diagnosis, treatment, and prognosis of PPS based on a combination of literature data and personal experience. The limited literature on the subject suggests that PPS is relatively common but insufficiently recognized. PPS is probably similar to psychogenic nonepiteptic seizures (PNES), in which a long delay to diagnosis worsens the prognosis. A detailed history is of paramount importance for the diagnosis. The key feature in the history of patients with PPS is the occurrence of frequent, long attacks of apparent TLOC with closed eyes. The diagnosis is certain when a typical event is recorded during a tilt-table test with simultaneous blood pressure (BP), heart rate and video-electroencephalographic recordings. Home video and BP recording during an attack can be very useful. The diagnosis should be communicated to the patient in a way that is clear, understandable and does not cause offense. Although treatment options have not been investigated formally, the literature on PNES suggests that cognitive behavioral therapy is beneficial. (Cardiol J 2014; 21, 6: 658-664)

Key words: syncope, psychogenic pseudosyncope
\end{abstract}

\section{Introduction: Psychogenic apparent loss of consciousness}

Transient loss of consciousness (TLOC) is a common clinical problem, consisting of three major groups: syncope, epileptic seizures, and psychogenic attacks, along with a rest group of remaining symptoms like mimics and rare disorders $[1,2]$. The 2009 European Society of Cardiology (ESC) Guidelines on syncope define TLOC as an 'apparent loss of consciousness' [2]. The word 'apparent' was explicitly added to allow psychogenic disorders to be included. In TLOC, due to syncope and epileptic seizures consciousness is undeniably lost, whereas there is no demonstrable cerebral dysfunction in psychogenic TLOC. For that reason such attacks might be classified as wholly separate from seizures and syncope, which was the case in the first ESC guidelines on syncope. They were later bundled because syncope, seizures and psychogenic attacks can be mistaken for one another and feature in the same differential diagnosis.

Patients who suffer from recurrent episodes of psychogenic TLOC can present with a wide

Address for correspondence: Dr J. Gert van Dijk, Department of Neurology and Clinical Neurophysiology, Leiden University Medical Centre, Leiden, the Netherlands, e-mail: J.G.van_Dijk@lumc.nl

Received: 05.09.2014 Accepted: 23.09.2014 
range of clinical symptoms. Some attacks are characterized by pronounced movements resembling epileptic seizures, generally labelled psychogenic non-epileptic seizures (PNES). When there are no discernible movements, the attacks are more easily mistaken for syncopal events. Labels for these attacks include psychiatric syncope, psychogenic syncope, pseudosyncope and psychogenic pseudosyncope (PPS). By definition [2], syncope is caused by cerebral hypoperfusion so this term should not be used for psychogenic attacks as they are not accompanied by changes in brain circulation. We prefer PPS because, analogous to PNES, it describes what the attack mimics while also indicating its nature.

PNES and PPS share the same underlying psychological disorder, but the difference in symptoms affects how the patient is diagnosed and managed. Patients with PNES are likely to be referred to neurologists, among whom PNES is well-known. The prevalence of PNES ranges from $18 \%$ in patients with seizures in a community study [5] up to $32 \%$ in patients in epilepsy clinics [6]. Patients with PPS are more likely to be referred to cardiologists in search for a cause of the presumed syncope. Table 1 lists the prevalence of various causes of TLOC in a number of cohort studies. Compiling diagnoses from 10 syncope units resulted in a mean rate of PPS of $4 \%$, but the prevalence varied greatly between series: several large cohort studies reported $0 \%$ PPS whereas others report a prevalence of up to $12 \%$. This wide range in the prevalence of PPS suggests that it is possibly insufficiently recognized, as has been suggested by others $[14,15]$. Publications

Table 1. Relative frequencies of diagnosis in syncope units. The table describes finding of the major apparent transient loss of consciousness (TLOC) categories. Note that percentages per study need not add to $100 \%$, as some categories used in the papers may have been left out. Several large cohort studies reported no cases of psychogenic syncope (PPS). Adapted from Wieling et al. [3].

\begin{tabular}{|c|c|c|c|c|c|c|c|c|c|}
\hline Source & $\mathbf{N}$ & Setting & $\begin{array}{c}\text { Classification } \\
\text { system }\end{array}$ & $\begin{array}{l}\text { VVS } \\
(\%)\end{array}$ & $\begin{array}{l}\mathrm{OH} \\
(\%)\end{array}$ & $\begin{array}{c}\text { Cardiac } \\
(\%)\end{array}$ & $\begin{array}{c}\text { Epileptic } \\
\text { seizures (\%) }\end{array}$ & $\begin{array}{l}\text { PPS } \\
(\%)\end{array}$ & $\begin{array}{c}\text { Unexplained } \\
(\%)\end{array}$ \\
\hline $\begin{array}{l}\text { Brignole et al., } \\
2003 \text { [4] }\end{array}$ & 279 & $\begin{array}{c}\text { ED with } \\
\text { syncope unit } \\
\text { (6 centers) }\end{array}$ & ESC 2001 & 56 & 4 & 8 & $\leq 15^{2}$ & & 16 \\
\hline $\begin{array}{l}\text { Strano et al., } \\
2005 \text { [7] }\end{array}$ & 521 & Outpatient & $\begin{array}{l}\text { Syncope } \\
\text { is TLOC }{ }^{1}\end{array}$ & 53.6 & 6.3 & 2.5 & 1.3 & 2.9 & 8.4 \\
\hline $\begin{array}{l}\text { Brignole et al., } \\
2006 \text { [8] }\end{array}$ & 712 & $\begin{array}{l}19 \text { general } \\
\text { hospitals }\end{array}$ & ESC 2001 & 65 & 10 & 13 & $\leq 6^{2}$ & & 5 \\
\hline $\begin{array}{l}\text { Ammirati et al., } \\
2008 \text { [9] }\end{array}$ & 96 & $\begin{array}{c}\text { In- and } \\
\text { outpatients }\end{array}$ & ESC 2009 & 65 & 1 & 6 & $1^{3}$ & 1 & 18 \\
\hline $\begin{array}{l}\text { Brignole et al., } \\
2010 \text { [10] }\end{array}$ & 941 & $\begin{array}{l}9 \text { general } \\
\text { hospitals }\end{array}$ & ESC 2004 & 67 & 4 & 6 & 1 & 1 & 18 \\
\hline $\begin{array}{l}\text { Mitro et al., } \\
2011 \text { [11] }\end{array}$ & 501 & $\begin{array}{l}\text { Teaching } \\
\text { hospital }\end{array}$ & ESC 2009 & 46.2 & 4.8 & 35.3 & 0 & 1.4 & 10.9 \\
\hline $\begin{array}{l}\text { Sousa et al., } \\
2013 \text { [12] }\end{array}$ & 245 & $\begin{array}{l}\text { General } \\
\text { hospital, } \\
\text { in- and } \\
\text { outpatient }\end{array}$ & ESC 2009 & 52.2 & 15.6 & 20.0 & 0 & 0 & 12.2 \\
\hline $\begin{array}{l}\text { Shin et al., } \\
2013 \text { [13] }\end{array}$ & 128 & $\begin{array}{l}\text { ED, training } \\
\text { hospital }\end{array}$ & $\begin{array}{l}\text { 'Largely } \\
\text { ESC 2009' }\end{array}$ & 65.5 & 11.7 & 8.2 & 0 & 0 & 12.5 \\
\hline $\begin{array}{l}\text { Wieling, 2014, } \\
\text { unpublished }\end{array}$ & 1651 & $\begin{array}{c}\text { Outpatient } \\
\text { tertiary } \\
\text { referrals }\end{array}$ & $\begin{array}{c}\text { ESC } \\
2001-2009\end{array}$ & 67.5 & 14.9 & 0.8 & 0.8 & 10.2 & 5.7 \\
\hline $\begin{array}{l}\text { Van Dijk, 2014, } \\
\text { unpublished }\end{array}$ & 174 & $\begin{array}{c}\text { Outpatient } \\
\text { tertiary } \\
\text { referrals }\end{array}$ & ESC 2009 & 54.6 & 19.0 & 0.6 & $4.6^{4}$ & 12.1 & 6.3 \\
\hline Mean and range & & & & $\begin{array}{c}59.3 \\
(46.2- \\
-67.5)\end{array}$ & $\begin{array}{c}9.1 \\
(1- \\
-19.0)\end{array}$ & $\begin{array}{c}10.4 \\
(0.6- \\
-35.3)\end{array}$ & $\begin{array}{c}1.1 \\
(0-4.6)\end{array}$ & $\begin{array}{c}3.6 \\
(0- \\
-12.1)\end{array}$ & $\begin{array}{c}11.3 \\
(5-18)\end{array}$ \\
\hline
\end{tabular}

ED - Emergency Department; ESC — European Society of Cardiology; OH — orthostatic hypotension; VVS — vasovagal syncope

'Syncope defined as 'transient loss of consciousness with loss of postural muscle tone'

'Includes epileptic seizures, psychogenic pseudosyncope and other conditions

${ }^{3}$ Carotid sinus syndrome + epilepsy

${ }^{4}$ Includes 'epileptic syncope', i.e. asystole due to an epileptic seizure 
on PPS are also scarce. This could have a number of explanations: (1) PPS is indeed very rare, (2) It is not recognized and patients are diagnosed with an 'unexplained syncope' instead, or (3) The subject is not considered exciting enough from a scientific point of view.

\section{Etiology of PPS}

PNES and PPS can be regarded as conversion disorder, a disease that is characterized by neurologic symptoms (in this case apparent loss of consciousness) that are not caused by a neurologic disease, but cause distress and/or impairment [16]. Psychological factors or life events such as trauma, interpersonal conflicts, and recent or old stressors may be associated with onset of conversion disorder. However, psychological factors and trauma are not always reported by patients, nor are they specific to conversion disorder, and many patients with conversion symptoms may not have identifiable psychological stressors. There is some evidence that altered preconscious threat processing causes a state of hypervigilance in patients who suffer from PNES [17]. During psychogenic apparent TLOC, heart rate (HR) and blood pressure (BP) are significantly increased [18]. This suggests that the episodes are accompanied by acute psychological stress [19]. PPS occurs in both sexes at all ages, although it appears to be more common in young women [18].

\section{Diagnosing PPS: History taking}

The importance of an accurate diagnosis is well established in the literature on PNES [20] but has not yet been explored in PPS. In PNES, a diagnostic delay can have serious adverse effects, even including death [21]. The delay until the correct diagnosis is typically stated as being several years [20]. Misdiagnosed PNES patients will be started on anti-epileptic drugs, and only the failure of a treatment response will in time prompt physicians to reconsider the diagnosis. The prognosis of PNES is worse as the delay to diagnosis is longer [22]. Once PNES is diagnosed there is a strong reduction in emergency department visits, hospital admissions, ambulance calls, magnetic resonance imaging scans, computed tomography scans and electroencephalography (EEG), implying that there are economic benefits to making a timely diagnosis $[23,24]$. The delay between attack onset and diagnosis in PPS has not been studied in depth but may be shorter than in PNES, as no erroneous drug treatment will be started. Still, a deleterious effect of a long delay seems as likely as in PNES.

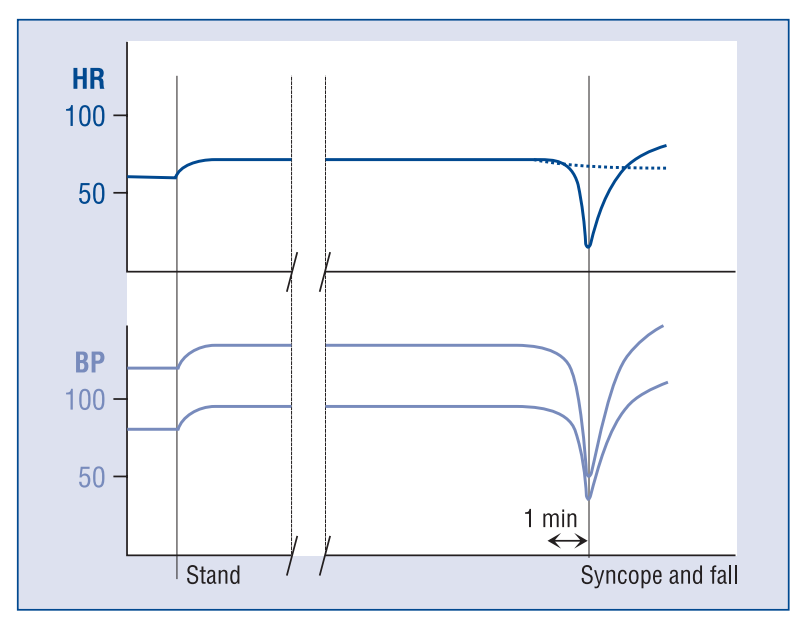

Figure 1. Typical tilt-table measurements of a patient with vasovagal syncope (right). The start of clinically apparent transient loss of consciousness (TLOC) is marked with a black line. Both heart rate (HR) and blood pressure (BP) show an accelerating drop and reach their minimum around the start of TLOC.

Due to the transient nature of TLOC, attacks are not likely to be witnessed by doctors, and the presence of amnesia makes an eyewitness account crucial. Unfortunately, distressed eye-witnesses tend to overlook or inaccurately recall salient features [25]. Accounts are probably more reliable as more attacks have been witnessed, but even then physicians may not know which signs and symptoms to ask for. Recently, we have described the semiology of PPS based on the analysis of consecutive episodes of tilt-evoked psychogenic apparent TLOC. In these observed attacks of PPS, the eyes were virtually always closed (97\%) during apparent TLOC, in contrast to vasovagal syncope (VVS) $(7 \%)$ (Figs. 1, 2). Typically, PPS was characterized by a sudden loss of muscle tone (e.g., falling, dropping the head); this was less common in VVS [18]. In contrast, jerking movements were rarely seen in PPS, but occurred in approximately $60 \%$ of patients with VVS [26]. Finally, PPS can be distinguished from VVS using the duration of apparent TLOC, which is longer in PPS. When it lasts longer than $1 \mathrm{~min}$, PPS is far more likely than VVS [18].

Our personal experience with the history of approximately 100 cases fits well with these observations: attacks are frequent, may often occur more than once a day, and last for a long time. The high number and long duration of attacks often allow reliable eyewitness accounts, yielding descriptions of the attack as an unresponsive and immobile state. Eyewitnesses may describe 


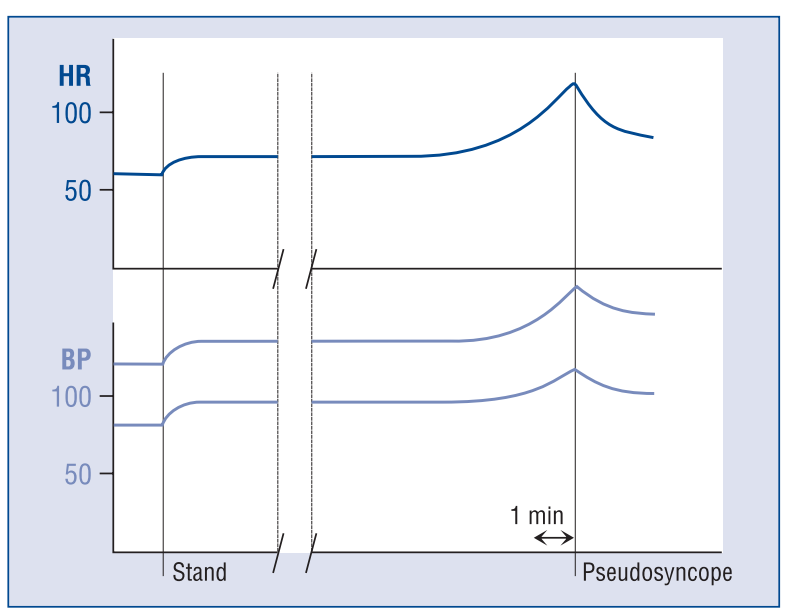

Figure 2. Typical tilt-table measurements of a patient with psychogenic pseudosyncope. The start of clinically apparent transient loss of consciousness (TLOC) is again marked with a black line. Both heart rate $(\mathrm{HR})$ and blood pressure (BP) increase well before the attack, reaching a maximum at the start of clinically apparent TLOC.

attacks lasting $30 \mathrm{~min}$ or even longer. Oddly, many physicians will still consider syncope as a cause, even though global cerebral hypoperfusion lasting $30 \mathrm{~min}$ is not compatible with a normal neurological state immediately afterwards. When asked about the patient's posture during an attack, witnesses may report a sleep-like state, with perhaps an arm under the head and closed eyes. Witnesses may even report seeing the eyes move behind the eyelids. Facial color is either reported as normal or slightly pale, but the extreme pallor seen in VVS is never described. In contrast to patients with VVS, those with PPS often report that they lack prodromal features. As a consequence, they are not able to prevent TLOC by sitting or lying down. Early on, patients may be seen by ambulance personnel or brought to emergency rooms. It is important to ask whether a BP measurement was obtained during apparent unconsciousness. Even when such an ictal measurement was normal, the implications for the diagnosis, in excluding syncope and pointing towards PPS, are often left undiscussed.

Over time, relatives will refrain from calling an ambulance, having learned that this does not result in a diagnosis or treatment. Early attacks are accompanied by extreme distress around the attack in relatives, over time giving way to unrest about the lack of diagnosis and stress about the consequences rather than about the attacks themselves.
Of note, patients themselves may not always have a complete amnesia for the event; some may hear part of what is going on around them, but without an ability or inclination to act. This valuable diagnostic information may remain hidden unless it is asked for specifically. PPS can cause physical trauma, so neither the absence nor the presence of trauma is diagnostically reliable.

The literature on the semiology of PNES is more extensive than that of PPS and provides insights that may help the recognition of PPS as well. A number of signs that can be used to distinguish PNES from epilepsy have been identified with the use of prolonged video-EEG recordings. Signs with a $>90 \%$ specificity for PNES include: long attack duration, closed eyes during apparent TLOC, a fluctuating course, asynchronous or side-to-side movements, pelvic thrusting and ictal weeping. Conversely, stertorous breathing and postictal confusion are more than $90 \%$ specific for epilepsy [27]. It should be noted that this only held for video observations, not for eyewitness accounts [25].

\section{Diagnosing PPS: Additional tests}

While it is possible to make the diagnosis from the history alone in typical cases of PPS, additional tests serve two purposes: to confirm the diagnosis, which also excludes other diagnoses and, perhaps most importantly, to convince patients, relatives and other physicians that the attacks are psychological in nature.

Both PNES and PPS can be diagnosed with certainty when there are no signs of cerebral dysfunction during an adequately documented attack. Recognition of the episode as a typical event by the patient or a relative present is an important requirement to prevent false-positive test results. In the case of PNES, this is usually done with the use of continuous EEG monitoring, in which case the absence of epileptiform EEG phenomena is considered the gold standard [28]. Sometimes, additional video analysis is warranted to exclude frontal lobe seizures that may occur without discernible EEG changes [29]. The gold standards to differentiate PPS from true syncope are the absence of BP low enough to cause unconsciousness, and a normal EEG during the attack [2]. Unfortunately, BP cannot be monitored continuously for long periods as easily as EEG, making it harder to obtain an ictal measurement in PPS. However, PPS is amenable to suggestion and can be provoked with the use of induction techniques or placebo maneuvers, leading to an attack in $90 \%$ of patients with PPS [15]. 
Tilt-table testing with continuous HR, BP, EEG and video monitoring is particularly useful: the tilting maneuver is sufficiently suggestive to elicit apparent TLOC in $81 \%$ of patients with PNES [30]. Furthermore, this approach enables the clinician to investigate the major causes of TLOC in one comprehensive test. HR and BP data can be used to rule syncope as a cause of TLOC, whereas video-EEG can be used to exclude epilepsy. Finally, the availability of video data not only helps in analyzing the semiology of the episode at a later time point, but can also be used to review the test together with the patient and a relative and confirm that a representative attack was captured. A clinical suspicion of PPS is a recognized indication for a tilt table test by the ESC [2].

Transcranial Doppler ultrasound of cerebral circulation has been advocated in combination with tilt-table testing to diagnose PPS [31]. When there is normal cerebral blood flow during apparent TLOC, syncope can be ruled out as a cause. However, normal cerebral perfusion does not rule out epilepsy and systemic BP and HR suffice to differentiate PPS from syncope.

PPS does not exclude additional somatic diagnoses [32]. In a longitudinal cohort of tilt-table induced PPS, $29 \%$ of patients showed a mixed pattern of PPS and VVS [18]. In this respect PPS also resembles PNES: the co-occurrence of epileptic seizures and PNES is well-known [20].

Mobile phones with video recording capability are a valuable tool to obtain objective information. If the nature of the attacks remains unclear after the first outpatient visit, we generally recommend that relatives of the patient try to make video recordings of the attacks. Furthermore, relatives are instructed to pay particular attention to the duration of unresponsiveness and the state of eye closure. The high frequency and long duration of the attacks make it likely that the attacks can be documented in this way. For the same reasons relatives may succeed in taking a BP recording with an automatic wrist device.

\section{Communication of the diagnosis}

Interview studies in PNES patients have shown that receiving the diagnosis is characterized by conflicting emotions, making it difficult to accept the neurologist's explanation. Patients need to integrate their diagnosis into a personal narrative in order to accept it [33]. Great care should therefore be taken to communicate in a manner that is clear and understandable and does not cause offense [34]. It is important to emphasize that the physician communicating the diagnosis does not think that attacks involve willful deceit. Instead, we stress that (1) Patients are not "crazy" and do not produce attacks voluntarily: the attacks happen to them just like syncope or epilepsy would; (2) The attacks cause distress and 3) Psychogenic attacks are much more common than people think. In our experience, the psychological nature of the attacks is usually accepted by patients and relatives, provided that enough time is taken for explanation. There is some debate in the literature on whether past trauma should be brought up as a potential cause, as this may be traumatic for patients and a clear history of trauma is not always present [33]. Most experts suggest that potential psychological causes should be brought up in very general terms, e.g., "we often see them in patients who are under a lot of stress" [35]. In our experience, such generalized statements are usually sufficient for patients to bring up past or actual traumatic experiences, provided that an environment of trust has been established. This then paves the way for a further referral for treatment of conversion disorder. We typically offer a repeat visit in 1 or 2 weeks to repeat key elements and to allow patients and relatives to ask questions.

\section{Treatment and prognosis of PPS}

The clinical picture of a typical PPS sufferer is one of an individual in severe distress; the patient should receive prompt and adequate treatment accordingly. Unfortunately, systematic, long-term follow-up data of the natural course of PPS or on the effect of psychotherapy is not available.

From the PNES literature, there is evidence that receiving the diagnosis has a substantial short-term beneficial effect, with approximately one third of patients becoming seizure free and a majority experiencing a significant reduction. However, long-term follow-up studies show that a majority of patients relapse after an initial good response to the diagnosis (reviewed in [20]).

The efficacy of various treatments for PNES has recently been reviewed [36]. The efficacy of cognitive behavioral therapy had the highest level of evidence, including one pilot randomized controlled trial comparing cognitive behavioral therapy with standard medical care. Other interventions with efficacy in uncontrolled trials included augmented psychodynamic interpersonal psychotherapy, group psychodynamic psychotherapy, group psycho-education, and selective serotonin reuptake 
inhibitors (SSRI). A pilot study on the SSRI sertraline showed a non-significant trend towards lower PNES event frequencies [37]. This was followed up by a multi-center randomized but unblinded clinical trial that compared cognitive behavioural therapy with and without flexible-dose sertraline to treatment as usual for PNES. Cognitive behavioral therapy resulted in improvement but the sertraline and usual treatment groups did not [38].

However, the most relevant treatment parameter is probably quality of life and perhaps occupational status, rather than attack frequency [39]. The scarce literature studying these parameters suggests that they rarely show improvement in PNES [20].

Data on the prognosis of PPS are not available. In PNES, several factors have been shown to have a positive influence on long-term prognosis (reviewed in [35]): the absence of severe psychiatric comorbidity, identifiable acute psychological trauma preceding the onset of PNES, living independently, a normal IQ, higher socio-economic class, being female, younger age, no past history of violence and a short history of PNES [22].

\section{Conclusions}

PPS is a serious condition with a dramatic impact on the quality of life. There are suggestions in the literature that it is insufficiently recognized and that this likely causes a delay in treatment with a potential negative effect on the outcome. PPS should be considered in all patients who suffer from episodes of apparent TLOC of unknown origin. A detailed history is of paramount importance for the diagnosis. Important aspects of the history are frequency, duration and eye closure: frequent, long attacks with the eyes closed during apparent TLOC are pathognomonic for PPS. The diagnosis can be made with certainty when a typical event is recorded during a tilt-table test with simultaneous $\mathrm{BP}, \mathrm{HR}$ and video EEG recordings. Ictal home video and $\mathrm{BP}$ recording can be very useful. Once the diagnosis is made, it should be communicated to the patient in a way that is understandable and does not cause offense. Although treatment options have not been investigated in well-designed randomized clinical trials, there is some evidence from the literature on PNES that cognitive behavioral therapy is beneficial.

Conflict of interest: None declared

\section{References}

1. van Dijk JG, Thijs RD, Benditt DG, Wieling W. A guide to disorders causing transient loss of consciousness: Focus on syncope. Nature reviews. Neurology, 2009; 5: 438-448.

2. Moya A, Sutton R, Ammirati F et al. Guidelines for the Diagnosis and Management of Syncope (version 2009). The Task Force for the Diagnosis and Management of Syncope of the European Society of Cardiology (ESC). Eur Heart J, 2009; 30: 2631-2671.

3. Wieling $\mathrm{W}$, van Dijk $\mathrm{N}$, de Lange FJ et al. History taking as a diagnostic test in patients with syncope: Developing expertise in syncope. Eur Heart J, 2014 [In press].

4. Brignole M, Disertori M, Menozzi C et al. Management of syncope referred urgently to general hospitals with and without syncope units. Europace, 2003; 5: 293-298.

5. Kotsopoulos I, de Krom M, Kessels FG et al. The diagnosis of epileptic and non-epileptic seizures. Epilepsy Res, 2003; 57: 59-67.

6. Hubsch C, Baumann C, Hingray C et al. Clinical classification of psychogenic non-epileptic seizures based on video-EEG analysis and automatic clustering. J Neurol Neurosurg Psychiatry, 2011; 82: 955-960.

7. Strano, S, Colosimo C, Sparagna A et al. Multidisciplinary approach for diagnosing syncope: A retrospective study on 521 outpatients. J Neurol Neurosurgery Psychiatry, 2005; 76: 1597-1600.

8. Brignole M, Ungar A, Bartoletti A et al. Standardized-care pathway vs. usual management of syncope patients presenting as emergencies at general hospitals. Europace, 2006; 8: 644-650.

9. Ammirati F, Colaceci R, Cesario A et al. Management of Syncope: Clinical and Economic Impact of a Syncope Unit. Europace, 2008; 10: $471-476$.

10. Brignole M, Ungar A, Casagranda I et al. Prospective multicentre systematic guideline-based management of patients referred to the syncope units of general hospitals. Europace, 2010; 12 : 109-118.

11. Mitro P, Kirsch P, Valočik G, Murín P. A prospective study of the standardized diagnostic evaluation of syncope. Europace, 2011; 13: $566-571$.

12. Sousa P, Marques N, Faria R et al. Syncope unit: experience of a center using diagnostic flowcharts for syncope of uncertain etiology after initial assessment. Portuguese J Cardiol, 2013; 32: 581-591.

13. Shin TG, Kim JS, Song H, Jo IJ, Sim MS, Park SJ. Standardized approaches to syncope evaluation for reducing hospital admissions and costs in overcrowded Emergency Departments. Yonsei Medical J, 2013; 54: 1110-1118.

14. Luzza F, Di Rosa S, Pugliatti P, Andò G, Carerj S, Rizzo F. Syncope of psychiatric origin. Clin Autonomic Res, 2004; 14: 26-29.

15. Benbadis, Selim R, Chichkova R. Psychogenic pseudosyncope: An underestimated and provable diagnosis. Epilepsy Behavior, 2006; 9: 106-110.

16. American Psychiatric Association. 2010. Proposed Revision | APA DSM-5. http://www.dsm5.org/ProposedRevisions/Pages/proposedrevision. .aspx? rid $=165$.

17. Bakvis P, Roelofs K, Kuyk J, Edelbroek P, Swinkels W, Spinhoven P. Trauma, stress, and preconscious threat processing in patients with psychogenic nonepileptic seizures. Epilepsia, 2009; 50: 1001-1011. 
18. Tannemaat MR, van Niekerk J, Reijntjes RH, Thijs RD, Sutton R, van Dijk JG. The semiology of tilt-induced psychogenic pseudosyncope. Neurology, 2013; 81: 752-758.

19. Gregg ME, James J E, Matyas TA, Thorsteinsson EB. Hemodynamic profile of stress-induced anticipation and recovery. Int J Psychophysiology, 1999 34: 147-162.

20. Bodde NMG, Brooks JL, Baker GA et al. Psychogenic non-epileptic seizure: Definition, etiology, treatment and prognostic issues: A critical review. Seizure, 2009; 18: 543-553.

21. Reuber M, Baker GA, Gill R, Smith DF, Chadwick DW. Failure to recognize psychogenic nonepileptic seizures may cause death. Neurology, 2004; 62: 834-835.

22. Buchanan N, Snars J. Pseudoseizures (non epileptic attack disorder): Clinical management and outcome in 50 patients. Seizure, 1993; 2: 141-146.

23. Jirsch, JD, Ahmed SN, Maximova K, Gross DW. Recognition of psychogenic nonepileptic seizures diminishes acute care utilization. Epilepsy Behavior, 2011; 22: 304-307.

24. Razvi S, Mulhern S, Duncan R. Newly diagnosed psychogenic nonepileptic seizures: health care demand prior to and following diagnosis at a first seizure clinic. Epilepsy Behavior, 2012; 23: 7-9.

25. Thijs RD, Wagenaar WA, Middelkoop HA, Wieling W, van Dijk JG. Transient loss of consciousness through the eyes of a witness. Neurology, 2008; 71: 1713-1718.

26. Van Dijk JG, Thijs RD, van Zwet E, Tannemaat MR, van Niekerk J, Benditt DG, Wieling W. The semiology of tilt-induced reflex syncope in relation to electroencephalographic changes. Brain. J Neurol, 2014; 137 (Part 2): 576-585.

27. Goldstein L, Mellers J. Recent developments in our understanding of the semiology and treatment of psychogenic nonepileptic seizures. Current Neurology and Neuroscience Reports, 2012;12: 436-444.
28. LaFrance WC Jr. Psychogenic nonepileptic seizures. Curr Opinion Neurol, 2008; 21: 195-201.

29. LaFrance WC Jr., Benbadis SR. Differentiating frontal lobe epilepsy from psychogenic nonepileptic seizures. Neurologic Clin, 2011; 29: 149-162.

30. Zaidi A, Crampton S, Clough P, Fitzpatrick A, Scheepers B. Head-up tilting is a useful provocative test for psychogenic non-epileptic seizures. Seizure, 1999; 8: 353-355.

31. Raj V, Rowe A, Fleisch S, Paranjape S, Arain A, Nicolson S. Psychogenic pseudosyncope: Diagnosis and management. Autonomic Neuroscience: Basic Clin, 2014: doi:10.1016/ /j.autneu.2014.05.003.

32. Khalil K, Kanjwal Y, Karabin B, Grubb B. Psychogenic syncope? A cautionary note. Pacing and Clinical Electrophysiology. PACE, 2009; 32: 862-865.

33. Thompson R, Isaac CL, Rowse G, Tooth CL, Reuber M. What is it like to receive a diagnosis of nonepileptic seizures? Epilepsy Behavior, 2009; 14: 508-515.

34. Stone J, Campbell K, Sharma N, Carson A, Warlow CP, Sharpe M. What should we call pseudoseizures? The patient's perspective. Seizure, 2003; 12: 568-572.

35. Reuber M, Mitchell AJ, Howlett SJ, Crimlisk HL, Grünewald RA. Functional symptoms in neurology: Questions and answers. J Neurol Neurosurgery Psychiatry, 2005; 76: 307-314.

36. Baslet G. Psychogenic nonepileptic seizures: A treatment review. What have we learned since the beginning of the millennium? Neuropsychiatric Disease Treatment, 2012; 8: 585-598.

37. LaFrance WC Jr, Keitner GI, Papandonatos GD et al. Pilot pharmacologic randomized controlled trial for psychogenic nonepileptic seizures. Neurology, 2010; 75: 1166-1173.

38. LaFrance WC Jr, Baird GL, Barry JJ et al.; for the NES Treatment Trial (NEST-T) Consortium. Multicenter Pilot Treatment Trial for Psychogenic Nonepileptic Seizures: A Randomized Clinical Trial. JAMA, 2014: doi:10.1001/jamapsychiatry.2014.817.

39. Reuber M, House A. Treating patients with psychogenic non-epileptic seizures. Curr Opinion Neurol, 2002; 15: 207-211. 